\title{
Human Skin Aryl Hydrocarbon Hydroxylase
}

\author{
INDUCTION BY COAL TAR
}

\author{
David R. Bickers and ATtallah KaPPas, Division of Dermatology, Case Western \\ Reserve University, School of Medicine, Cleveland, Ohio 44106, and The \\ Rockefeller University Hospital, New York 10021
}

\begin{abstract}
A B S TRACT Coal tar products, which are widely used in treating dermatologic disease, contain numerous polycyclic aromatic hydrocarbons, including 3,4-benzo[a]pyrene (BP). BP is among the most potent environmental chemical carcinogens and is known to evoke tumors in the skin of experimental animals and perhaps also of man. In this study the effect of cutaneous application of coal tar solution (U. S. Pharmacopeia) on aryl hydrocarbon hydroxylase (AHH) activity in the skin of patients usually treated with this drug was investigated. AHH, a cytochrome P-450 dependent carcinogen-metabolizing enzyme appears to play an important role in the activation of polycyclic hydrocarbons into reactive moieties that can bind to DNA and that may directly induce cancer. Application of coal tar solution to human skin caused a two to fivefold induction of cutaneous AHH in nine subjects. In further studies, the incubation of human skin with coal tar solution in vitro also caused variable induction of cutaneous AHH. Maximum responses in both systems occurred after $24 \mathrm{~h}$ and enzyme activity in vitro was time- and tissue- and substrate-concentration dependent. Studies in experimental animals showed that topical application of coal tar solution caused induction of $\mathrm{AHH}$ in skin and, after percutaneous absorption, in liver as well. Assay of several defined constituents of coal tar for AHH induction showed that BP was the most potent inducer of $\mathrm{AHH}$ tested. These studies indicate that topical application of coal tar solution in doses ordinarily used in treating dermatologic disease causes induction of $\mathrm{AHH}$ in human skin and suggest that such induced enzymatic activity could relate to carcinogenic responses to this agent in skin or, after percutaneous absorption, in other tissues as well.
\end{abstract}

A portion of this work was presented at the 35th Annual Meeting of the American Federation for Clinical Research, April 1978. Clin. Res. 26: 297A. (Abstr.)

Received for publication 20 June 1978.

\section{INTRODUCTION}

Coal tar, a by-product of the gasification and distillation of coal, is a widely used therapeutic agent in clinical practice, particularly in the treatment of chronic dermatoses such as eczematous dermatitis and psoriasis. White (1) was among the first to stress the therapeutic efficacy of crude coal tar and subsequently this agent has become a mainstay in the treatment of numerous inflammatory skin diseases. Goeckerman $(2,3)$ suggested that the combination of skin application of coal tar followed by exposure to ultraviolet radiation was especially effective in treating psoriasis and this regimen continues to be the most common method of managing this disease to date.

The first evidence that some human cancers are caused by exposure to environmental agents was the report in 1775 by Sir Percival Pott which showed an increased incidence of scrotal cancers in chimney sweeps exposed to soot (4). Almost $150 \mathrm{yr}$ elapsed before studies in experimental animals verified that repetitive application of crude coal tar to the rabbit ear produced skin cancers (5). Subsequently, at least one constituent isolated from coal tar, (3,4-benzo[a]pyrene), was shown to be carcinogenic for animal skin (6-8).

Extensive epidemiologic studies in man have clearly shown an increased incidence of skin cancer in workers after chronic occupational exposure (usually 20-30 yr) to coal tar products (9-11). The occurrence of tumors in human skin after prolonged exposure to medications containing coal tar products has also been reported though with much less frequency than that associated with occupational exposure (12-15).

Cutaneous metabolism of polycyclic hydrocarbons such as benzo[a]pyrene $(\mathrm{BP})^{1}$ after skin application,

${ }^{1}$ Abbreviations used in this paper: AHH, aryl hydrocarbon hydroxylase; BP, benzo[a]pyrene; OH-BP, hydroxybenzo[a]pyrene. 
has long been thought to play a role in chemical carcinogenesis (16-18). Recent studies in experimental animals suggest that aryl hydrocarbon hydroxylase (AHH), an enzyme present in the skin, may be a critical determinant of cutaneous carcinogenic responses to polycyclic aromatic hydrocarbons such as BP by transforming the parent compound into proximately reactive metabolites (19): In previous studies from this laboratory it has been shown that AHH is present in human neonatal foreskin and that the enzyme is induced after incubation of cutaneous tissue in vitro with the polycyclic hydrocarbon benzanthracene $(20,21)$. However, no previous studies have assessed the possible AHH induction effect of polycyclic hydrocarbons in human skin in vivo.

Because coal tar application to the skin is a widely used and accepted treatment for dermatologic diseases in man and because coal tar contains polycyclic aromatic hydrocarbons known to be inducers of $\mathrm{AHH}$ in other tissues, it seemed important to assess the AHH induction effect of the application of coal tar to the skin of patients undergoing treatment with this agent. In further studies, the in vitro system previously developed to study AHH activity in neonatal foreskin was extended to adult human skin in an effort to better define selected aspects of the enzyme induction effect of coal tar $(20,21)$. Studies were also performed in experimental animals to determine whether skin application of coal tar causes induction of hepatic drug metabolism after percutaneous absorption of the topically applied compound. In addition, preliminary experiments were conducted in an effort to identify which, if any, of several major known constituents of coal tar can induce cutaneous $\mathrm{AHH}$ activity.

\section{METHODS}

Patients. Six patients with generalized psoriasis and three patients with severe atopic dermatitis whose disease had not been treated topically for at least 3 mo were studied. All subjects were nonsmokers and had received no systemic medication for at least 1 mo before the study. Standard coal tar solution (U. S. Pharmacopeia) which consists of crude coal tar diluted to $20 \%$ with ethanol and polysorbate 80 was used. $100 \mu \mathrm{l}$ of coal tar solution was applied to clinically unaffected skin, approximately $1 \mathrm{~cm}$ in diameter, of the lower lumbar region and the area immediately covered with a simple gauze dressing. A second skin area at least $10 \mathrm{~cm}$ away was not treated or was treated with the vehicle alone $(100 \mu \mathrm{l})$ and covered with the same type of gauze dressing. $24 \mathrm{~h}$ later, after local anesthesia with xylocaine (1\%), a 6-mm punch biopsy was obtained from the coal tar-treated and the control areas, and each immediately placed in $9 \mathrm{vol}$ of ice-cold $0.1 \mathrm{M}$ potassium phosphate buffer, $\mathrm{pH}$ 7.40.

Enzyme assay. The skin samples were minced finely with scissors and homogenized with a Polytron Tissue Grinder (Brinkmann Instruments, Inc., Westbury, N. Y.) and groundglass homogenizer. AHH activity was measured in whole skin homogenate as described previously (22). The incubation flask contained $2 \mu \mathrm{m}$ of NADPH, $3 \mu \mathrm{m}$ of $\mathrm{MgCl}_{2}$, $0.5 \mathrm{ml}$ of skin homogenate (3-5 $\mathrm{mg}$ protein), $100 \mathrm{~nm}$ of $\mathrm{BP}$ in $0.05 \mathrm{ml}$ acetone, and $0.1 \mathrm{M} \mathrm{K}_{2} \mathrm{HPO}_{4}-\mathrm{KH}_{2} \mathrm{PO}_{4}$ buffer ( $\mathrm{pH}$ 7.40 ) to a total volume of $1.05 \mathrm{ml}$. Samples were incubated for $30 \mathrm{~min}$ in the dark at $37^{\circ} \mathrm{C}$. Hydroxylation of $\mathrm{BP}$ was expressed as picomoles hydroxybenzo[a]pyrene (OH-BP) formed with a standard solution of 3-OH-BP generously provided by Dr. Harry Gelboin. All results were corrected for recoveries $(65-70 \%)$ obtained when the 3-OH-BP standard was added to skin homogenate and extracted in the usual manner. Protein was determined by the method of Sutherland et al. (23).

Culture technique. This was based upon the previously described procedure $(21,22)$. Eagle's minimum essential medium containing Earle's balanced salt solution (Grand Island Biological Co., Grand Island N. Y.), fetal bovine serum (Microbiological Associates Walkersville, Md.), glutamine, streptomycin, nystatin, and penicillin $\mathrm{G}$ was used. $0.05 \mathrm{ml}$ of coal tar solution was dispersed in $10 \mathrm{ml}$ of calf serum and the resulting suspension was added to $190 \mathrm{ml}$ of complete medium, shaken at $42^{\circ} \mathrm{C}$ for $16 \mathrm{~h}$ in the dark and passed through a Millipore filter (Millipore Corp., Bedford, Mass.). This was necessary to assure maximum solubilization of the relatively water-insoluble coal tar components. Control medium without coal tar was treated in the same manner.

Skin from human breasts obtained at surgery for breast neoplasms was immediately placed in cold control medium. Under aseptic conditions, subcutaneous fat was trimmed away and skin samples weighed, minced finely with scissors, and placed either in control medium or in the medium containing coal tar solution. Unless otherwise specified, the skins were maintained for $24 \mathrm{~h}$ at $37^{\circ} \mathrm{C}$ in a humidified atmosphere of $5 \% \mathrm{CO}_{2}$ in air. At the end of the incubation, medium containing the minced skin was centrifuged, and the pellet washed four times with 5-10 ml of $0.1 \mathrm{M} \mathrm{K}_{2} \mathrm{HPO}_{4}-\mathrm{KH}_{2} \mathrm{PO}_{4}$ buffer (pH 7.40). The washed skin pellet was then homogenized and the AHH assay performed on whole skin homogenate as above.

Animal studies. These were designed to assess the possible systemic effects of skin application of coal tar solution. Coal tar solution $(0.05 \mathrm{ml})$ was applied to the skin of neonatal rats (4-6 days of age) and $24 \mathrm{~h}$ later $\mathrm{AHH}$ activity measured in skin and in liver. In further studies, an effort was made to identify selected defined constituents of coal tar which might have an AHH induction effect in skin after topical application. For these studies $1 \%$ solutions of BP, anthracene, phenanthrene, naphthalene, and pyrene in acetone or benzene were prepared. Animals were treated with skin application of $0.05 \mathrm{ml}$ of each solution and cutaneous AHH activity determined $24 \mathrm{~h}$ later.

\section{RESULTS}

Effect of coal tar solution on human skin AHH in vivo. The clinical diagnosis and AHH induction response of the patients treated with coal tar are shown in Table I. Skin application of coal tar caused induction of cutaneous AHH activity that varied from two- to fivefold over the enzyme activity in untreated skin areas. There was no sex difference in inducibility nor did there appear to be any differences in induction between individuals with psoriasis or with atopic dermatitis. The AHH induction response of each individual patient is shown in Fig. 1. Basal levels of enzyme activity varied over at least a twofold range but since these levels of skin AHH enzyme activity are measured near the maximum sensitivity of the fluores- 
TABLE I

Clinical Profile of Patients

\begin{tabular}{llllc}
\hline Patient & Sex & Age & \multicolumn{1}{c}{ Diagnosis } & Skin AHH inducibility \\
\hline & & $y r$ & & - fold \\
D.W. & F & 38 & Psoriasis & 4.2 \\
V.C. & F & 59 & Psoriasis & 5.4 \\
H.B. & M & 42 & Psoriasis & 3.6 \\
J.C. & M & 67 & Psoriasis & 2.4 \\
R.T. & M & 71 & Psoriasis & 5.2 \\
A.S. & F & 37 & Psoriasis & 3.8 \\
W.H. & M & 22 & Atopic dermatitis & 4.0 \\
L.S. & M & 25 & Atopic dermatitis & 3.7 \\
V.D. & F & 20 & Atopic dermatitis & 3.3 \\
\end{tabular}

cent method, it is likely that basal levels may vary over a considerably wider range. Relative inducibility of human skin AHH by coal tar did not appear to be a function of the basal level of the enzyme.

Effect of in vitro incubation of human skin with coal tar. $24 \mathrm{~h}$ after incubation with coal tar in vitro induction of human skin $\mathrm{AHH}$ activity also occurred. These data are shown in Fig. 2. The induction response and both basal and induced levels of AHH acitivty were considerably less than those observed in the in vivo studies. This is probably caused by differences in absorption of the coal tar into the skin and by the lower dose of coal tar used in the in vitro experiments. The lower dose of coal tar for the in vitro studies was necessitated by the relative insolubility of this substance in the culture medium.

Time course of the AHH induction response in human skin incubated with coal tar in vitro. In these studies pooled samples of human skin (derived from

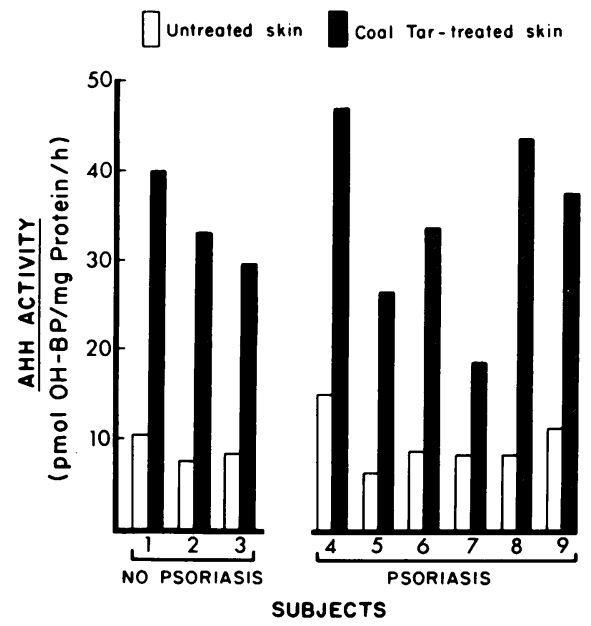

FIGURE 1 AHH induction in human skin by coal tar solution. Coal tar solution $(100 \mu \mathrm{l})$ was applied to the skin and $24 \mathrm{~h}$ later the site was biopsied. Skin homogenate was prepared and AHH activity determined.

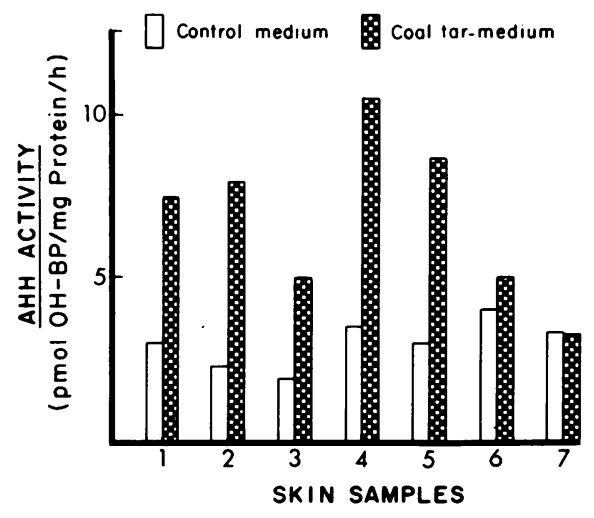

FIGURE 2 AHH induction in human skin in vitro. Minced skin from human breasts obtained at surgery was incubated for $24 \mathrm{~h}$ in culture medium, in the presence or absence of coal tar. $\mathrm{AHH}$ activity was then determined in whole skin homogenate.

the tissue obtained at breast surgery) were minced and divided into two groups. One group was incubated in control tissue culture medium and the second group incubated in medium that contains coal tar. Skin samples were removed at various times after the start of incubation and AHH activity determined in whole skin homogenate. The results are shown in Fig. 3. There was an initial lag phase lasting about $8 \mathrm{~h}$ followed by a $16-\mathrm{h}$ period of linearly increasing $\mathrm{AHH}$ activity after which enzyme activity diminished. Because maximum AHH activity occurred after $24 \mathrm{~h}$ of incubation in coal tar-containing medium, this time was used for further studies of the induced skin enzyme.

Properties of human skin AHH after incubation with coal tar in vitro. The effect of varying the amount of tissue protein concentration on the AHH assay is shown in Fig. 4. AHH activity was proportional to skin protein up to a concentration of 5-7.5 $\mathrm{mg}$ of protein in both

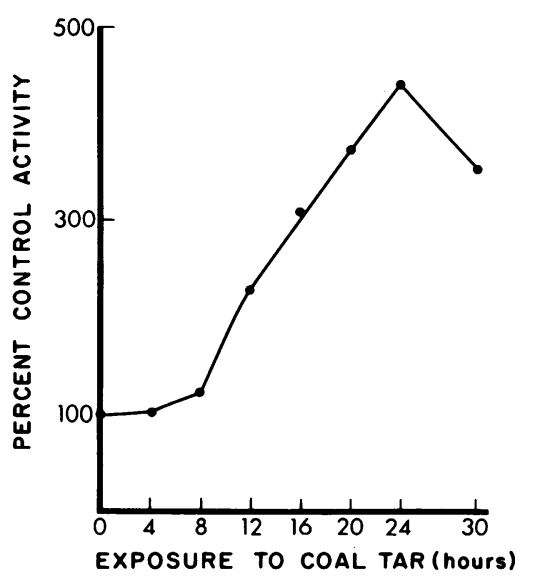

Figure 3 Time-course of the AHH induction response of human skin cultured in vitro with coal tar solution. (Control AHH activity was $4.2 \pm 0.5 \mathrm{pmol} \mathrm{OH}-\mathrm{BP} / \mathrm{mg}$ protein per $\mathrm{h}$.) 


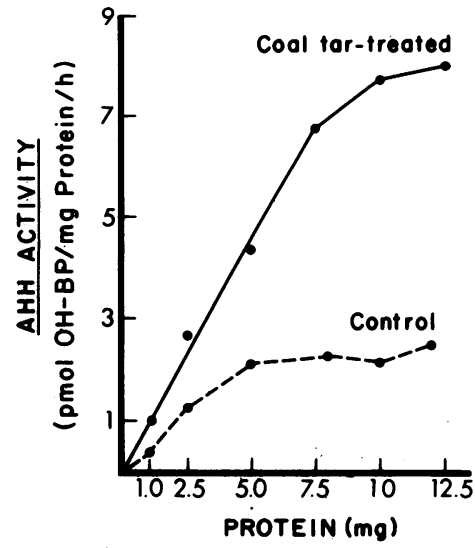

FIGURE 4 AHH activity in human skin as a function of tissue protein concentration. Skin was incubated in the presence or absence of coal tar for $24 \mathrm{~h}$. Skin homogenates were prepared, diluted to the appropriate protein concentration, and $\mathrm{AHH}$ activity determined.

control and coal tar-incubated skin. The effect of varying the time of incubation in the AHH assay is shown in Fig. 5. The reaction was linear up to $30 \mathrm{~min}$ and under these conditions was proportional to substrate (BP) concentrations up to $50 \mathrm{~nm}$ (Fig. 6).

Microsomal AHH in other tissues such as liver is known to require NADPH and molecular oxygen for catalytic activity and to be inhibited by carbon monoxide. As shown in Fig. 7, after incubation with coal tar in vitro, human skin AHH also required NADPH and oxygen, was inhibited at least $80 \%$ by carbon monoxide, and was inhibited by 7,8-benzoflavone, a known inhibitor of AHH in other tissues (24). These data suggest that human skin $\mathrm{AHH}$, like the enzyme in other human and animal tissues, is cytochrome P-450

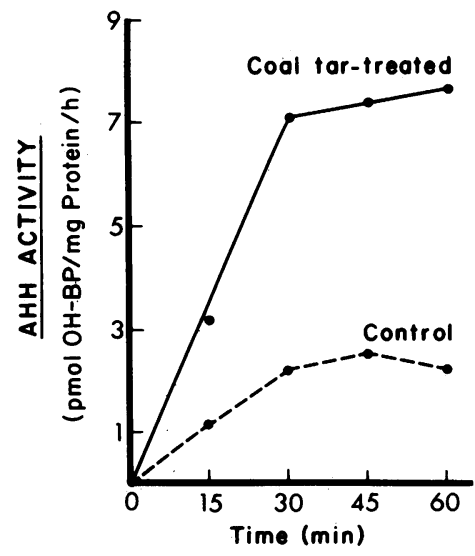

FIgURE 5 AHH activity in human skin as a function of the time of incubation with substrate (BP). Skin was treated for $24 \mathrm{~h}$ in vitro in the presence or absence of coal tar. Skin homogenates were prepared and $\mathrm{AHH}$ activity determined at various incubation times.

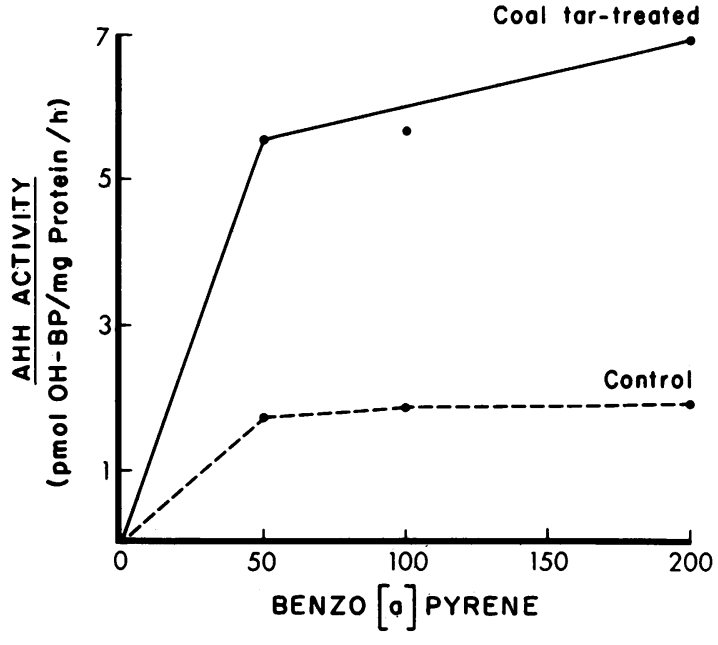

FIGURE 6 AHH activity in human skin incubated in the presence or absence of coal tar for $24 \mathrm{~h}$ as a function of substrate concentration. Skin homogenates were prepared and $\mathrm{AHH}$ activity determined with various amounts of BP.

dependent. P-450 and P-448 refer to the general class of microsomal heme proteins which serve as the terminal oxygenase in oxidative metabolism of drugs and various chemicals.

Animal studies. These experiments were carried out to determine whether topically applied coal tar solution could induce AHH in liver as well as skin of treated animals. Our previous studies have shown marked and sustained hepatic induction under similar conditions with the polychlorinated biphenyls (22). Coal tar solution diluted to $1 \%$ concentration $(0.05$ $\mathrm{ml}$ ) was applied to neonatal rat skin; $24 \mathrm{~h}$ later skin and liver AHH activity were determined. The results are shown in Table II. After topical application of the solution, there was a greater than 10-fold induction of skin AHH activity. Hepatic AHH activity also increased markedly after skin application of the coal tar solution indicating that substantial percutaneous absorption of the solution had occurred. In further studies an effort was made to identify selected constituent(s) of coal tar capable of inducing cutaneous AHH. The results of these experiments are shown in Table III. Of the defined constituents of coal tar that were examined, BP was the most potent inducer. However, pyrene and anthracene also caused significant induction of cutaneous $\mathrm{AHH}$ though of a considerably lesser magnitude than that caused by BP. It is clear from these studies that at least three known constituents of therapeutic coal tar are capable of inducing AHH activity in skin after topical application.

\section{DISCUSSION}

AHH is a cytochrome P-450 dependent microsomal enzyme that catalyzes the oxidative biotransformation of 


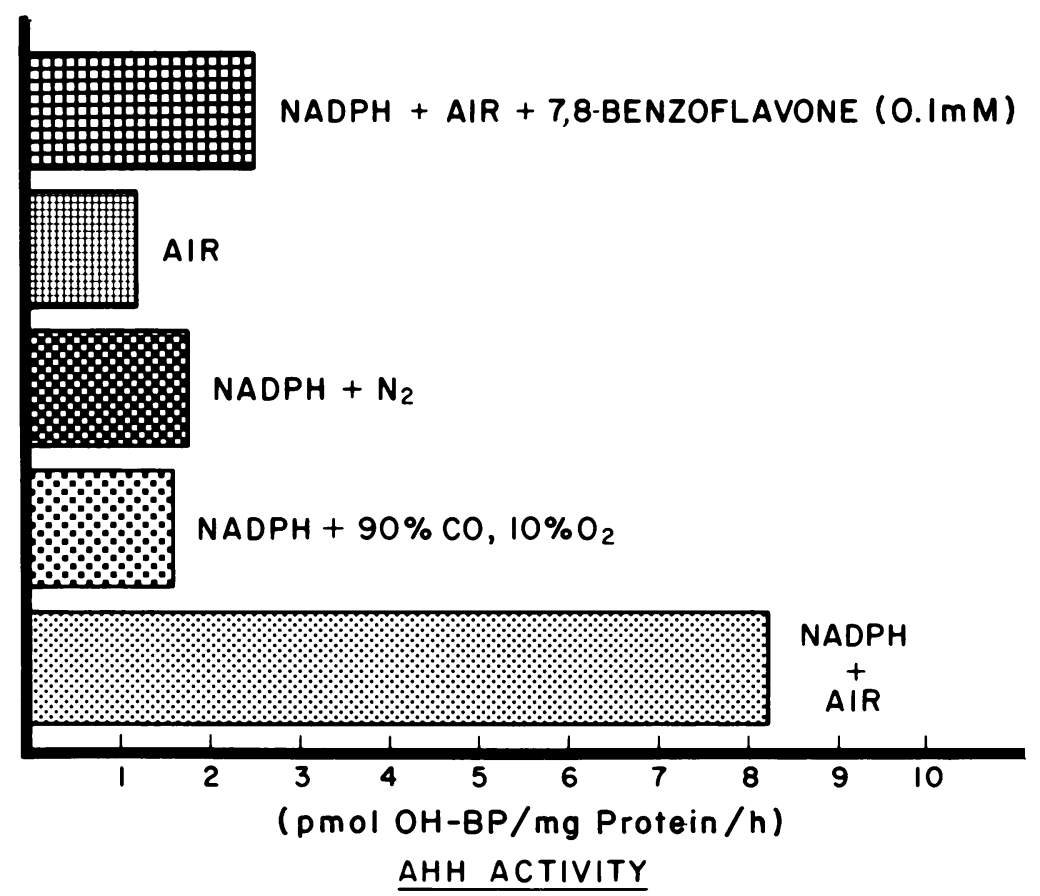

FIgURE 7 Characteristics of human skin AHH after incubation with coal tar in vitro for $24 \mathrm{~h}$. Enzyme activity of the complete reaction mixture is shown in the bottom panel. For each of the experiments with different gases, incubation flasks containing the complete reaction mixture (see Methods) were flushed for 5 min with the appropriate gas and immediately stoppered. AHH activity was then determined. CO and nitrogen each inhibited human skin AHH by at least $80 \%$. NADPH was also required for catalytic activity. 7,8-Benzoflavone, a known inhibitor of $\mathrm{AHH}$ activity in other tissues, also inhibited the human skin enzyme by at least $75 \%$.

polycyclic aromatic hydrocarbon carcinogens. The enzyme has been found in numerous human tissues including liver $(25,26)$, lung (27), placenta (28), pulmonary alveolar macrophages (29), lymphocytes (30), and skin $(20,21)$. Recent studies have suggested that the inducibility of AHH by environmental carcinogens such as BP may correlate with susceptibility to tumorigenesis in experimental animals and in human populations though the precise relationship between AHH inducibility and susceptibility to chemical carcinogen-

TABLE II

Effect of Coal Tar Solution on Neonatal Rat Skin and Liver AHH after Cutaneous Application

\begin{tabular}{ccccc}
\hline \multicolumn{4}{c}{ AHH activity* $^{2}$} \\
\hline \multicolumn{2}{c}{ Skin } & & \multicolumn{2}{c}{ Liver } \\
\cline { 5 - 6 } Control & Coal tar & & Control & Coal tar \\
\hline $26.3 \pm 1.9 \$$ & $298 \pm 13 \S$ & & $750 \pm 35$ & $16,300 \pm 899 \S$
\end{tabular}

\footnotetext{
* Expressed as mean $\pm \mathrm{SE}$ of six rats.
}

$\ddagger$ Picomoles OH-BP per milligram protein per hour.

$\$$ Results significantly different from respective controls $(P<0.05)$. esis remains controversial (31-34). Nebert et al. (35) suggested that inducibility of AHH by polycyclic hydrocarbons in inbred strains of mice is inherited as an autosomal dominant trait and further, that skin

\section{TABLE III}

Effect of Selected Constituents of Coal Tar on Skin AHH Activity in Neonatal Rats

\begin{tabular}{llc}
\hline \multirow{2}{*}{\multicolumn{1}{c}{ Constituent* }} & \multicolumn{2}{c}{ AHH activity } \\
\cline { 2 - 3 } & \multicolumn{1}{c}{ Control } & Treated \\
\hline Benzo[ $a$ ] pyrene & $28.7 \pm 2.8 \S$ & $329 \pm 29^{\prime \prime}$ \\
Anthracene & $29.1 \pm 2.1$ & $60.7 \pm 5.1^{\prime \prime}$ \\
Pyrene & $27.7 \pm 3.6$ & $87.2 \pm 10.2^{\prime \prime}$ \\
Phenanthrene & $23.9 \pm 2.0$ & $22.2 \pm 1.7$ \\
Naphthalene & $21.8 \pm 2.6$ & $19.8 \pm 2.2$ \\
\hline
\end{tabular}

* Each was diluted in acetone or benzene to a concentration of $1 \%$ and $0.05 \mathrm{ml}$ applied to the skin. Controls received the appropriate vehicle alone.

$\ddagger$ Expressed as mean $\pm \mathrm{SE}$ of six rats.

$\S$ Expressed as picomoles OH-BP per milligram protein per hour.

"Results significantly different from respective controls $(P<0.05)$. 
tumor induction by topically applied polycyclic hydrocarbons occurs much more frequently in species such as the C57-black mouse in which inducible AHH activity is also present. Kinoshita and Gelboin (31) have also shown that pretreatment with inhibitors of AHH activity such as 7,8 benzoflavone markedly reduces the tumorigenic effect of dimethylbenzanthracene.

The importance of metabolism of BP in inducing cutaneous tumors in experimental animals is clear from studies showing that selected metabolites of BP, for example BP-7,8-dihydrodiol, have a tumorigeneic effect equal to or greater than that of the parent compound (36). Recent studies have shown that in addition to AHH activity, a second microsomal enzyme, epoxide hydrase is present in human skin and in the skin of experimental animals (37). This enzyme converts AHH-produced epoxides of BP into dihydrodiols, which may then be oxidatively transformed a second time by cutaneous AHH resulting in the production of diol-epoxides. These diol-epoxides have been shown to bind covalently to DNA among other macromolecules, a process which is thought to be an initial link in the chain of events leading to tumor formation $(38,39)$.

The induction of tumors after chronic skin exposure to soot and other coal tar products was first reported more than 200 yr ago by Pott (4). Most coal tar-induced skin tumors have occurred on the scrotum or on cutaneous surfaces such as the hands and face which are repeatedly exposed. Epidemiologic studies in England have shown that the majority of skin tumors associated with exposure to coal tar products occurs in workers who have intense cutaneous exposure for extended periods of time, usually $20-30 \mathrm{yr}$ (9). It also appears that workers chronically exposed to coal tar products are at higher risk for the development of lung cancer and perhaps renal cancer, compared with agerelated controls (40). Whether this increased incidence of cancer is related to $\mathrm{AHH}$ or other enzyme activity in the target tissues has not been evaluated. It seems clear, however, that chronic exposure to coal tar products for many years is usually required before an increased incidence of human cancer can be shown to occur.

Coal tar derivatives are widely used in the treatment of common dermatologic diseases such as psoriasis and chronic eczematous dermatitis. Despite their widespread usage, the apparent incidence of skin cancers directly related to such therapy seems to be relatively low. However, there are a number of case reports which indicate that skin tumors have developed in patients who have repeatedly used large amounts of coal tar for extended periods (usually years). Greither et al. in reviewing the world literature were able to find at least 13 cases of skin cancer seemingly directly related to chronic application of coal tar products to the skin (41). The most frequent sites of the skin neoplasms were the genital areas (seven cases) and the exposed areas (six cases). In all cases the coal tar product had been chronically applied to the skin area in which tumor formation occurred.

Hodgson (12) was among the first to suggest that coal tar could cause skin cancer in patients treated with drugs that contain these products. He reported a single case of squamous cell carcinoma occurring in a 62-yr-old man treated for $7 \mathrm{yr}$ with twice daily application of liquor picis carbonis, a coal tar derivative. Berenblum (13) then showed that this solution was carcinogenic for mouse skin and suggested that the carcinogenicity was caused at least in part by the BP content of the product. Rook et al. (14) reported a patient in whom two squamous cell carcinomas of the thigh developed after $32 \mathrm{yr}$ of self-treatment with $3 \%$ crude coal tar.

In animal studies, Shabad et al. (15) showed that Locacorten-Tar (Ciba-Geigy Corp., Pharmaceuticals Div., Summit, N. J.), a skin cream that contains $1.5 \%$ coal tar, produced cutaneous tumors in $94 \%$ of mice treated with skin application of the drug. Hirohata et al. (42) have also examined the carcinogenicity of tar-containing medications in mouse skin. In their studies, some tar-containing medications were shown to contain as much as $1.5 \mathrm{mg}$ of BP per gram of drug wet weight. Their data suggested that the BP content of various tar-containing products correlates with the tumorigenicity of these agents for mouse skin; however, no assessment of $\mathrm{AHH}$ activity was carried out.

Other workers, however, with carefully chromatographed fractions of coal tar that contained no detectable BP, showed that these non-BP containing fractions of coal tar were tumorigenic in mouse skin (7). Poel and Kammer (43) applied different coal tar oils to mouse skin and found that oils without detectable BP were nonetheless tumorigenic. These studies suggest that the carcinogenicity of coal tar for skin of experimental animals may be caused by both BP and additional constituents.

The studies reported here have shown, for the first time, that application of a coal tar product to the skin of patients with dermatologic disease causes induction of AHH activity in cutaneous tissue. This induction response occurred with doses of a U. S. P.-listed coal tar preparation that are routinely used in treating these patients. The AHH induction response in human skin showed considerable variation which ranged from twoto fivefold. This is consistent with the concept that the induction response of $\mathrm{AHH}$ in cutaneous tissue may be, in part, determined by genetic factors. The small number of individuals studied, however, precludes more definitive interpretation at this time. We have also shown that incubation of human skin with coal tar 
in vitro causes considerable induction of cutaneous AHH activity; this induction is similar in most respects to that produced by skin application in vivo.

Our data also indicate that human skin $\mathrm{AHH}$ activity is dependent upon tissue and substrate concentration. Furthermore, the co-factor requirements for maximum activity of the skin enzyme are similar to those of cytochrome P-450 dependent enzymes in other tissues (44). Thus cutaneous AHH activity was markedly reduced in the absence of NADPH or oxygen and was inhibited by carbon monoxide. In addition, 7,8-benzoflavone, a known inhibitor of $\mathrm{AHH}$ in the skin of experimental animals, also inhibited human skin AHH (24).

Because our in vitro studies showed that incubation of human skin with a compound containing various polycyclic aromatic hydrocarbons causes measurable induction of cutaneous $\mathrm{AHH}$, it is possible that skin or perhaps fibroblasts grown from small biopsies of skin could be used to assess AHH activity and inducibility in human populations.

The results also show that application of coal tar to the skin of experimental animals causes induction of cutaneous AHH and, after percutaneous absorption induction of the hepatic enzyme as well. This is consistent with previous work from this laboratory which showed that skin application of the environmental pollutant chemicals polychlorinated biphenyls causes induction of cutaneous and hepatic AHH (22). Whether such percutaneous absorption of coal tar solution (or selected constituents) occurs in humans treated with this agent is not known but is certainly a possibility in patients who are repetitively treated with large amounts of the drug.

Coal tar is a complex mixture containing 10,000 or more compounds less than 500 of which have been identified. BP is present in most coal tar-containing medications in concentrations as high as $200 \mu \mathrm{g} / \mathrm{g}$ (42). Of the several constituents of coal tar which were tested for their effect on cutaneous AHH, BP had the most potent induction effect. However, at least two other constituents, anthracene and pyrene, also induced the cutaneous enzyme. This suggests that the total AHH induction effect of topically applied coal tar solution may be a summation of the induction effects of a number of separate chemicals in the solution.

Finally, these data indicate that human skin has inducible enzymes capable of responding to environmental chemicals and topically applied drugs. This further substantiates the concept that the skin functions as an active metabolic interface between the body and the environment. Such metabolic activity may be one of the important determinants of the pharmacologic potency of topically applied drugs. Furthermore, enzyme activity of this type, which generates reactive metabolic intermediates, may also be a critical factor in carcinogenic and(or) toxic responses in skin and perhaps, after percutaneous absorption, in other tissues as well. The sheer size of the skin ( $3-5 \%$ body weight) suggests that drug-metabolizing enzymes present in cutaneous tissue could be one determinant of the body's total metabolic response to exogenous drugs and chemicals. Thus the traditional concept of the skin as a passive barrier between the body and the environment may require modification as further information accumulates concerning enzyme activity in this tissue.

\section{ACKNOWLEDGMENTS}

We wish to thank Ms. Anne LaGania for her assistance in preparing this manuscript.

This work was supported by research grants from the National Institute of Environmental Health Sciences (ES1900, ES-1041, and ES-1055) and by General Clinical Research Center grants (RR 00102 and RR 00645).

\section{REFERENCES}

1. White, C. J. 1921. Crude coal tar in Dermatology. Arch. Dermatol. 4: 796-806.

2. Goeckerman, W. H. 1925. Treatment of psoriasis. Northwest Med. 24: 399.

3. Goeckerman, W. H. 1931. Treatment of psoriasis: continued observations on the use of crude coal tar and ultraviolet light. Arch. Dermatol. 24: 446-450.

4. Pott, P. 1775. Cancer Scroti. In Chiurgical Observations. The Chiurgical Works of Percival Pott. Hawes, Clark and Collings, London.

5. Yamagiwa, K. and K. Ichikawa. 1918. Experimental study of the pathogenesis of carcinoma. J. Cancer Res. 3: 1-29.

6. Cook, J. W., C. R. Hewett, and I. Hieger. 1933. The isolation of a cancer-producing hydrocarbon from coal tar. J. Chem. Soc. (Lond.). I: 395-405.

7. Berenblum, I., and R. Schoental. 1947. Carcinogenic constituents of coal tar. Br. J. Cancer. 1: 157-165.

8. Kennaway, E. 1955. The identification of a carcinogenic compound in coal tar. Br. Med. J. II: 749-752.

9. Henry, S. A. 1947. Occupational cutaneous cancer attributable to certain chemicals in industry. $\mathrm{Br}$. Med. Bull. 4: 389-401.

10. Hueper, W. C. 1963. Chemically induced skin cancers in man. N. I. H. Monograph. 10: 377-391.

11. Falk, H. L., P. Kotin, and A. Mehler. 1964. Polycyclic hydrocarbons as carcinogens for man. Arch. Environ. Health. 8: 721-730.

12. Hodgson, G. 1948. Epithelioma following local treatment of pruritus ani with liquor picis carbonis. $\mathrm{Br} . J$. Dermatol. 60: 282.

13. Berenblum, I. 1948. Liquor picis carbonis (BP), a carcinogenic agent. Br. Med. J. II: 601 .

14. Rook, A. J., G. A. Gresham, and R. A. Davis. 1956. Squamous epithelioma possibly induced by the therapeutic application of tar. Br.J. Cancer. 10: 17-23.

15. Shabad, L. M., A. J. Khesina, and A. B. Linnik. 1970. Possible carcinogenic hazards of several tars and of LocaCorten tar ointment. Spectro-fluorescent investigations and experiments in animals. Int. J. Cancer. 6: 314-318.

16. Boyland, E., and F. Weigert. 1947. Metabolism of carcinogenic compound. Br. Med. Bull. 4: 354-359. 
17. Weigert, F., G. Calcutt, and A. K. Powell. 1947. The course of the metabolism of benzopyrene in the skin of the mouse. Br. J. Cancer. 1: 405-410.

18. Weigert, F., G. Calcutt, and A. K. Powell. 1946. Production of metabolic benzopyrene derivatives in vitro. Nature (Lond.). 158: 417.

19. Gelboin, H. V., F. Wiebel, and L. Diamond. 1970. Dimethylbenzanthracene tumorigenesis and aryl hydrocarbon hydroxylase in mouse skin. Inhibition by 7,8 benzoflavone. Science (Wash. D. C.). 170: 169-171.

20. Levin, W., A. H. Conney, A. P. Alvares, I. Merkatz, and A. Kappas. 1972. Induction of benzo(a)pyrene hydroxylase in human skin. Science (Wash. D. C.). 176: 419-420.

21. Alvares, A. P., A. Kappas, W. Levin, and A. H. Conney. 1973. Inducibility of benzo(a)pyrene hydroxylase in human skin by polycyclic hydrocarbons. Clin. Pharmacol. Ther. 14: 30-40.

22. Bickers, D. R., A. Kappas, and A. P. Alvares. 1974. Differences in inducibility of hepatic and cutaneous drug metabolizing enzymes and cytochrome P-450 by polychlorinated biphenyls and 1, 1, 1-trichloro-2, 2-bis(p-chlorophenyl)-ethane (DDT).J. Pharmacol.Exp. Ther. 188: 300-309.

23. Sutherland, E., C. F. Cori, R. Haynes, and N. S. Olsen. 1949. Purification of the hyperglycemic-glycogenolytic factor from insulin and from gastric mucosa.J. Biol. Chem. 180: 825-837.

24. Diamond, L., R. McFall, J. Miller, and H. V. Gelboin. 1972. The effects of two isomeric benzoflavones on aryl hydrocarbon hydroxylase and the toxicity and carcinogenicity of polycyclic hydrocarbons. Cancer Res. 32: 731-736.

25. Kuntzman, R., L. C. Mark, L. Brand, N. Jacobson, W. Levin, and A. H. Conney. 1966. Metabolism of drugs and carcinogens by human liver enzymes. J. Pharmacol. Exp. Ther. 152: 151-156.

26. Kapitulnik, J., P. J. Poppers, and A. H. Conney. 1977. Comparative metabolism of benzo(a)pyrene and drugs in human liver. Clin. Pharmacol. Ther. 21: 166-176.

27. Prough, R. A., Z. Sipal, and S. W. Jakobson. 1977. Metabolism of benzo(a)pyrene by human lung microsomal fractions. Life Sci. 21: 1629-1636.

28. Juchau, M. R., N. G. Pederson, A. G. Fantel, and T. H. Shepard. 1973. Drug metabolism by placenta. Clin. Pharmocol. Ther. 14: 673-679.

29. McLemore, T. L., R. R. Martin, K. L. Topell, D. L. Busbee, and E. T. Cantrell. 1977. Comparison of aryl hydrocarbon hydroxylase induction in cultured blood lymphocytes and pulmonary macrophages. J. Clin. Invest. 60: 1017-1024.

30. Gurtoo, H. L., N. Bejba, and D. Minowada. 1975. Properties, inducibility and an improved method of analysis of aryl hydrocarbon hydroxylase in cultured human lymphocytes. Cancer Res. 35: 1235-1243.

31. Kinoshita, N., and H. V. Gelboin. 1972. Aryl hydrocarbon hydroxylase and polycyclic hydrocarbon tumorigenesis: Effect of the enzyme inhibitor 7,8 benzoflavone on tumorigenesis and macromolecule binding. Proc. Natl. Acad. Sci. U. S. A. 69: 824-828.

32. Kellerman, G., C. R. Shaw, and N. Luyten-Kellerman. 1972. Aryl hydrocarbon hydroxylase inducibility and bronchogenic carcinoma N. Engl. J. Med. 289: 934-937.

33. Burki, K., A. G. Liebelt, and E. J. Bresnick. 1973. Induction of aryl hydrocarbon hydroxylase in mouse tissues from a high and low cancer strain and their $F$ hybrids. J. Natl. Cancer Inst. 50: 370-376.

34. McLemore, T. L., R. R. Martin, D. L. Busbee, R. C. Richie, R. R. Springer, K. L. Topell, and E. T. Cantrell. 1977. Aryl hydrocarbon hydroxylase activity in pulmonary macrophages and lymphocytes from lung cancer and noncancer patients. Cancer Res. 37: 1175-1181.

35. Nebert, D. W., F. M. Goujon, and J. E. Gielen. 1972. Aryl hydrocarbon hydroxylase induction by polycyclic hydrocarbons: Simple autosomal trait in the mouse. $\mathrm{Na}$ ture (Lond.). 236: 107-110.

36. Levin, W., A. W. Wood, H. Yagi, D. M. Jerina, and A. H. Conney. 1976. ( \pm )-trans-7,8-dihydroxy-7,8-dihydrobenzo(a)pyrene: a potent skin carcinogen when applied topically to mice.Proc. Natl. Acad. Sci.U. S. A. 73: 3867-3871.

37. Oesch, F., H. Schumassmann, and P. Bentley. 1977. Specificity of human, rat and mouse skin epoxide hydratase towards K-region epoxides of polycyclic hydrocarbons. Biochem. Pharmacol. 27: 17-20.

38. Daudel, P., M. Duquesne, P. Vigny, P. L. Grover, and P. Sims. 1975. Fluorescence spectral evidence that benzo(a)pyrene-DNA products in mouse skin arise from diolepoxides. FEBS (Fed. Eur. Biochem. Soc.) Lett. 57: 250-253.

39. Koreeda, M., P. D. Moore, P. G. Wislocki, W. Levin, A. H. Conney, H. Yagi, and D. M. Jerina. 1978. Binding of benzo(a)pyrene 7,8-diol-9,10-epoxides to DNA, RNA and protein of mouse skin occurs with high steroselectivity. Science (Wash. D. C.). 199: 778-780.

40. Redmond, C. K., A. Ciocco, J. W. Lloyd, and H. W. Rush. 1972. Long-term mortality study of steelworkers. VI. Mortality from malignant neoplasms among coke oven workers. J. Occup. Med. 14: 621-629.

41. Greither, A., C. Gisbertz, and H. Ippen. 1967. Teerbehandlung und Krebs. Z. Haut-Geschlechtskr. 42: 631635.

42. Hirohata, T., Y. Masuda, A. Horie, and M. Kuratsune. 1973. Carcinogenicity of tar-containing skin drugs: animal experiment and chemical analysis. Gann. 64: 323-330.

43. Poel, W. E., and A. G. Kammer. 1957. Experimental carcinogenicity of coal tar fractions, The carcinogenicity of creosote oils. J. Natl. Cancer Inst. 18: 41-55.

44. Conney, A. H., and J. J. Burns. 1972. Metabolic interactions among environmental chemicals and drugs. Science (Wash. D. C.). 178: 576-585. 